\title{
A PERFORMANCE NARRATIVA DE UMA BLOGUEIRA: “TORNANDO-SE PRETA EM UM SEGUNDO NASCIMENTO"
}

\author{
Glenda Cristina Valim de MELO* \\ Luiz Paulo da MOITA LOPES**
}

- RESUMO: A web 2.0 propicia aos sujeitos sociais a possibilidade de contar suas histórias assim como de vê-las discutidas em novas formas de interação. Este artigo almeja apresentar os posicionamentos interacionais que constroem a performance narrativa de co-construção de raça de uma mulher negra no blog "Eu, Mulher Preta". O estudo se ampara nos aportes teóricos dos novos letramentos digitais, na concepção de raça proposta pelas Teorias Queer e na teorização de narrativa como performance. Para analisar a narrativa da blogueira como performance, o quadro analítico se ancora no construto de posicionamento interacional e nas pistas que marcam tal posicionamento na encenação da performance. Os resultados indicam que a narradora se posiciona interacionalmente como mulher preta. Identificamos, porém, um posicionamento interacional anterior ao renascimento como negra: o de mulher "branc[a] meio suj[a]". Observamos ainda que tais posicionamentos refletem duas performances discursivas conflitantes, uma que se aproxima e valoriza a negritude e outra que se distancia de sua origem. Esta investigação, baseando-se nas Teorias Queer, possibilita, também, tratar a questão racial como um traço performativo, colocando-a ao lado de gênero e sexualidade.

- PALAVRAS-CHAVE: Mulher negra. Teorias Queer. Blog. Narrativa como performance discursiva. Posicionamento interacional. Pistas indexicais.

As histórias não existem. O que existe, sim, é quem as conta. Javier Cercas (2007).

\section{Introdução}

Na Modernidade Recente, ${ }^{1}$ segundo Santos (2008), deparamo-nos com a pluralidade da vida social e com a transgressão. Em tal contexto, transgredir

* UNIFRAN - Universidade de Franca. Franca - SP - Brasil. 14.401-380 - glendamelo09@gmail.com

** UFRJ - Universidade Federal do Rio de Janeiro. Faculdade de Letras. Rio de Janeiro - RJ - Brasil. 21.941-590 moitalopes@pq.cnpq.br

1 Na literatura, encontramos outros termos que se referem à ideia de Segunda Modernidade. Giddens (1991) faz uso do termo Modernidade Reflexiva, em referência às transformações do mundo atual e ao momento de reflexão e reinvenção da vida contemporânea. Em relação às mesmas mudanças, Bauman (2001) emprega também o termo Modernidade Líquida e Rampton (2006) Modernidade Tardia. 
seria entrar em territórios considerados proibidos e "[...] pensar o que não deveria ser pensado, fazer o que não deveria ser feito" (PENNYCOOK, 2006, p. 74). Tais possibilidades afloram com o advento da web 2.0, visto que os sujeitos sociais e seus corpos podem se expor livremente, lutar pelos seus direitos, contestar as exclusões ou injustiças que presenciamos na sociedade de modo que possam contar suas histórias sem o receio de depreciação do mundo face a face, podendo ser, portanto, outros. Nos blogs e redes sociais, por exemplo, as chamadas minorias ${ }^{2}$ relatam suas vivências, exercem a cidadania e podem selecionar as lutas que valham à pena, segundo o seu contexto histórico-social e suas experiências. Dessa forma, o ambiente on-line pode contribuir para dar visibilidade também aos corpos ébanos, já que "[...] a Modernidade silenciou a diversidade das experiências humanas de sociabilidade em benefício de um projeto identitário único: branco, masculino e heterossexual." (MOITA LOPES, 2006, p. 291). Com o intuito de dar voz às mulheres negras, neste estudo, analisamos os posicionamentos interacionais de Preta, encenados em uma narrativa no blog "Eu, Mulher Preta", ${ }^{3}$ que constroem suas performances narrativas de mulher negra após os 20 anos.

Optamos por esse blog especificamente porque nele a participante conta, compartilha suas histórias, desconstrói sua performance de mulher branca, constrói suas performances narrativas como mulher negra, expõe sua voz sem receio de ter seus discursos desconsiderados e mostra sua face, sem ser taxada ou identificada negativamente por tais ações. Já a escolha pelas mulheres negras se deve ao fato de elas lutarem como candaces ${ }^{4}$ para saírem da invisibilidade, já que os censos, ${ }^{5}$ como os de 2000 e 2010, indicam que essas estão na última escala da pirâmide social. Aqui, tais negras são compreendidas como sujeitos sociais que se reinventam, cujas performances identitárias são constituídas por atos de fala performativos repetidos a cada discurso e marcados no corpo como veremos ao longo do artigo. Além disso, elas também são compreendidas como sendo perpassadas por gênero, sexualidade, classe social, nível de escolaridade, além de raça, como sugerem as propostas das Teorias Queer (SULLIVAN, 2003; BARNARD, 2004; SOMMERVILLE, 2000; MELO; MOITA LOPES, 2013).

2 O termo "minoria", neste artigo, é utilizado para aqueles que não têm igualdade de oportunidades de acesso e de direito no mundo social. Para mais informações sobre a população negra como minoria, <http://www. slideshare.net/laeserieufrj/relatrio-2009-2010>

3 O título do blog está no original, porque a participante, no momento de autorização para que a pesquisa fosse realizada, solicitou-nos que o título fosse mantido.

4 Segundo Bispo (2009), os gregos e romanos usavam o nome "candaces" para designar as rainhas africanas com as quais estabeleciam negócios. Elas governaram a região da Etiópia na antiguidade e simbolizavam o poder feminino de lutar pela sua cultura, seu território, conquistando respeito, espaço e também prosperidade.

5 Mais informações sobre os censos podem ser verificadas em: <http://www.ibge.gov.br/home/default.php>. 
Vale dizer que, nos estudos linguísticos, as vozes de tais candaces têm sido objeto de estudo de Costa de Paula (2003, 2010), Ferreira (2006, 2009), Moita Lopes (2003), Melo e Moita Lopes (2013) que abordam a questão racial em suas pesquisas. Como tais autores, visamos a construir um discurso no campo dos estudos da linguagem sobre as mulheres negras, mas partindo das propostas das Teorias Queer, ${ }^{6}$ que diferentemente da chamada Ciência da Raça e dos discursos da democracia racial (ver as críticas de SODRÉ, 1999; SULLIVAN, 2003; TELLES, 2003 a tais discursos), compreendem raça perpassada por gênero, sexualidade, classe social etc. Sendo assim, neste artigo, primeiro abordamos os novos letramentos digitais; a seguir, discutimos a questão racial pelas perspectivas Queer; depois, centramo-nos na questão da narrativa como construto teórico-metodológico; em seguida, introduzimos o contexto, metodologia de pesquisa e os construtos analíticos; e, finalmente, procedemos à análise.

\section{Os novos letramentos digitais}

Segundo Brockmeier e Oslon (2009), não há uma episteme única em se tratando de letramentos digitais e nem um consenso sobre seus sentidos. As várias áreas do saber discutem o tema e o termo apresenta conceituações novas e diversas. Neste estudo, eles são entendidos como a habilidade, a capacidade ou o saber lidar com as Tecnologias de Informação e Comunicação (TICs) em diversos contextos na procura do significado (MARTIN, 2008; LANKSHEAR; KNOBEL, 2008; BROCKMEIER; OSLON, 2009). Em outras palavras, os novos letramentos digitais são "[...] práticas sociais nos quais textos (trechos significativos de linguagem) são construídos, transmitidos, recebidos, modificados, compartilhados (e engajados de outras formas) por meio de processos que empregam códigos digitalizados eletronicamente." (DOBSON; WILLINSKY, 2009, p. 298).

Os avanços tecnológicos nos propiciam o acesso a recursos semióticos que podem possibilitar interagir com o outro sem restrições de tempo e de espaço. Com os novos letramentos digitais, colocamos nosso foco na web 2.0 e nos efeitos discursivos que tais dispositivos semióticos podem propiciar à vida de sujeitos sociais. Sendo assim, segundo Jenkins (2008, p. 43), "[...] entretenimento não é a única coisa que flui... Nossas vidas, relacionamentos, memórias, fantasias e desejos também fluem pelos canais da mídia."

Ademais, os sujeitos sociais contemporâneos se apropriam das diversas TICs e de recursos da web 2.0 e, ao assim fazerem, encontram outras possibilidades de contar histórias sobre quem são, como é o caso da participante desta investigação.

6 Ver Sullivan (2003), Louro (2004), Wilchins (2004), para conhecer os aportes teóricos que ancoram as Teorias Queer. 
Ela, por exemplo, ao se apropriar das ferramentas computacionais de todo o métier de elaboração de um blog, integra a sua narrativa a outros recursos semióticos multimodais que influenciam o seu modo de contar sua história e de se reconstruir.

Fazendo uso das palavras de Bruce e Bishop (2008, p. 699), os novos letramentos digitais e a sua apropriação são "[...] parte de se viver no mundo e não apenas uma habilidade adquirida em sala de aula." Também, compreendemos que essa apropriação das TICs possa promover novas formas de interação como as observadas em grupos, comunidades on-line, blogs, salas de bate-papo etc. Embasados em hooks (1994), mas considerando o contexto digital, entendemos que os participantes, além de outras ações discursivas, podem transgredir, quebrar barreiras, contestar e não aceitar as normalizações ou os binarismos identitários propostos pela Modernidade (MOITA LOPES; BASTOS, 2010). Podemos incluir nessa perspectiva as dicotomias raciais como branco versus negro ou negro consciente versus negro embranquecido, encontradas, por exemplo, em algumas comunidades virtuais ou sites voltados para negras/negros (MELO; MOITA LOPES, 2013). A desconstrução e a contestação de tais binarismos também são questionadas pelas Teorias Queer, vertente teórica que discutiremos a seguir.

\section{Perspectiva Queer de raça em contexto brasileiro}

A questão racial na diáspora africana no Brasil ainda é complexa, pois é senso comum a ideia de que somos determinados biologicamente, que a cor da pele diz quem somos e consequentemente os direitos e as oportunidades a que temos acesso. Os efeitos semânticos de discursos da escravidão, da abolição, da chamada Ciência da Raça e do mito da democracia racial ainda podem ser percebidos em contextos distintos do país, respeitando as particularidades de cada região, e fazem parte da constituição da sociedade brasileira racial, como indica a narrativa da participante desta pesquisa. Tais efeitos discursivos ainda constroem negras(os), em muitos contextos, como marginais, bandidos, não confiáveis, feios, incompetentes, incapazes para atividades intelectuais etc.

As Teorias Queer englobam uma perspectiva que objetiva contestar normas sedimentadas sejam elas de raça, gênero e/ou sexualidade (SOMMERVILLE, 2000; SULLIVAN, 2003; BUTLER, 2004; BARNARD, 2004; LOURO, 2004; WILCHINS, 2004). Elas visam a refletir também a respeito de uma política pós-identitária, despreocupada com a fixidez, a estabilidade, as normalizações e ainda buscam problematizar, segundo Louro (2004, p. 40), as "[...] noções clássicas de sujeito, de identidade, de agência e de identificação." Conforme já indicamos em Melo e Moita Lopes (2013), seguindo Sullivan (2003), Wilchins (2004), Loxley (2007), entendemos que as Teorias Queer se embasam no prisma foucaultiano de que o poder é exercido nas microrrelações; na concepção dos atos de fala performativos 
de Austin (1990); nos conceitos de iterabilidade e de citacionalidade propostos por Derrida (1988), em sua releitura dos atos de fala performativos de Austin; e, na perspectiva de desconstrução de Derrida (1988), que almeja desnaturalizar os binarismos com os quais opera a Modernidade na tradição ocidentalista.

Abordar a questão racial no Brasil pelos aportes teóricos Queer é focar nos discursos da escravidão, da abolição, da Ciência da Raça, de democracia racial (SODRÉ, 1999; MUNANGA, 1986; TELLES, 2003; HENRIQUE, 2007) e nos seus efeitos semânticos nas práticas sociais, contestando, desta forma, os discursos normalizadores sobre raça que visam apenas a desqualificar e inferiorizar negras(os) como sujeitos sociais. Eles têm sido, historicamente, propagados continuamente pela mídia e por outras instituições, assimilados e reproduzidos pela sociedade brasileira e seus efeitos discursivos são perceptíveis nas práticas sociais.

Nas vertentes Queer, ser negra ou amarela ou branca seria o resultado dos diversos atos de fala performativos a que negros, amarelos e brancos são constantemente expostos desde seu nascimento, ou seja, o sujeito social seria resultado dos efeitos discursivos que o constituem performativamente (SULLIVAN, 2003). Além disso, seguindo Derrida (1988), entendemos que tais atos são sedimentados pela iterabilidade e citacionalidade. Em outras palavras, a construção discursiva de raça é levada a efeito pelos atos de fala performativos da escravidão, da abolição, da Ciência da Raça, da democracia racial e miscigenação que pregam, por um lado, a inferioridade do negro e, por outro, a ausência de racismo e a igualdade de oportunidades para os brasileiros, independentemente de questões raciais. Transformar a mulher negra em sujeito social envolve desconstruir tais discursos cristalizados de raça na sociedade, assim como os discursos solidificados sobre gênero e sexualidade, possibilitando outras performances.

Pensando sobre a questão racial e sobre contestação de discursos que cristalizam binarismos, em relação às negras, deparamo-nos com os discursos que as inferiorizam e as erotizam. Como exemplo, podemos citar dois discursos hegemônicos sobre o cabelo dessas mulheres negras: o dos cabelos alisados e dos cabelos naturais. No primeiro, o alisamento é considerado como embranquecimento das negras; já no segundo, o cabelo ao natural indicaria a sua aceitação como negra. Segundo Costa de Paula (2010), em sua pesquisa de doutoramento, ambos discursos sustentam a lógica binária de desvalorização da mulher negra, já que, ao alisar os cabelos, ela se apagaria como negra e, ao mantê-los ao natural, ela se assumiria como negra.

Contudo, são excluídas dessa perspectiva outras possibilidades e motivações para a mudança de visual. Há todo um discurso racial que perpassa a questão e o embelezamento é deixado de lado. O alisamento, segundo 
Costa de Paula (2010, p.276), pode ser uma "subpolítica de afirmação e de desessencialização de performances", uma "estratégia para exercer uma ação performativa", cujas motivações podem ser as mais diversas, pois o cabelo por si não evoca "um sentido de valorização". Segundo a pesquisadora, o embelezamento do cabelo de uma forma ou de outra ou de formas diversas não transformaria uma negra em branca, pelo contrário, possibilitaria uma desestabilização da questão racial.

Outro discurso encontrado na sociedade é o da sensualidade e sexualidade das mulheres negras, consideradas "boas de cama", "gostosas", fogosas ou, nas palavras de Piza (1995, p. 58): "[...] o estereótipo da mulher negra sensual, sedutora, irresistível, atração para o pecado (masculino)." Segundo Carneiro (2003, p. 123), há um discurso e mito de que a mulher negra seria "[...] mais erótica ou mais ardente sexualmente do que as demais, crença relacionada às características do seu físico, muitas vezes exuberante." Tais discursos solidificados ainda coconstroem as mulheres negras como objeto sexual.

Salientamos que o contato de várias(os) negras(os) com os diversos discursos que essencializam e inferiorizam os corpos ébanos ocorre desde a infância. Embasados em Ferreira (2009), podemos dizer que, para esses corpos, a escola é o lugar onde se aprende que a cor da pele preta é marcada no corpo ou que ser diferente é um problema. Nela, muitos negros e negras ainda ouvem xingamentos, são excluídos e desmotivados a relatar o preconceito racial que sofrem da criança não negra. Nesse local de aprendizagem, dentro e fora da sala de aula, diversos corpos ébanos também aprendem que sua voz não deve ser considerada por professores(as), que, em grande parte, não sabem lidar com a questão do preconceito racial, suas ofensas e seus efeitos nas práticas sociais.

Compartilhando das perspectivas Queer, Sommerville (2000) e Barnard (2004) entendem que a sexualidade e o gênero não podem ser estudados sem incluir a questão racial e vice-versa. De acordo com os pesquisadores, os teóricos da raça tendem a centrar-se na raça em primeiro lugar; os de sexualidade a privilegiam e os estudiosos de gênero, por sua vez, olhariam primeiro esta categoria. Assim, se manteria a hegemonia de uma delas. Wilchins (2004) argumenta que uma análise que contempla uma única categoria isoladamente propiciaria uma visão incompleta do sujeito social, ou seja, ao olhar apenas para raça, não teríamos uma visão do todo, tanto da(o) negra(o) como da(o) não negra(o).

Ainda conforme o autor, "[...] não se é apenas a raça, deve-se aprender a ser de uma raça, inclusive - em certas circunstâncias - a passar a ser de uma raça [...]" (WILCHINS, 2004, p.116). Sendo assim, os atores sociais, devido às construções de seu ethos no mundo sócio-discursivo, saberiam como agir como negros, brancos etc. No mundo social, cobram-se dos atores performances equivalentes 
às características atribuídas pela psicologia e biologia. ${ }^{7}$ Desse modo, quando esse paradigma psicológico-biológico é quebrado nas práticas performativas, há uma surpresa.

Em outras palavras, as Teorias Queer questionam a questão racial perpassada unicamente pelos discursos da escravidão, da abolição, da Ciência da Raça e da democracia racial. Elas compartilham da perspectiva de que o sujeito social é constituído discursivamente pela integração entre raça, gênero, sexualidade, classe social, nível de escolaridade etc. Ademais, como construção social e discursiva, embasados em Sommerville (2000), Sullivan (2003), Butler (2004) e Barnard (2004), entendemos que ser mulher e negra também dependeria do momento sócio-histórico em que o sujeito social se inseriria, ou seja, estaria relacionado à identificação e à política, dessencializando toda a ideia de qualquer pureza racial, ou seja, tanto de branquitude como de negritude, ${ }^{8}$ sendo o último recorrente na narrativa de Preta, como veremos na análise.

\section{Narrativa como aporte teórico-metodológico}

Como sujeitos sociais, estamos habituados a contar, ler e ouvir histórias. Por meio delas, relatamos o cotidiano a outros por meio de narrativas seja face a face, pela televisão (via novelas, filmes ou séries), pelos dispositivos tecnológicos que nos propiciam acesso a comunidades de afinidades, blogs e outros.

Segundo Thornborrow e Coates (2005, p.01), o estudo da narrativa não é um privilégio apenas da área de literatura, ela é uma ferramenta de geração de dados ou um modo de investigação pesquisado por uma gama de áreas do saber como a antropologia, sociologia, psicologia social, linguística aplicada, sociolinguística e outras. O contar história é estudado desde Aristóteles (1992), que propôs que a narrativa tivesse início, meio e fim; passando, entre outros, por Propp (2006) em seus estudos sobre o conto de fadas e por Labov (1972), que analisou a estrutura da narrativa, propondo um conjunto de componentes que comporiam a história.

Nesta investigação, interessam-nos, no entanto, as perspectivas de alguns pesquisadores, por exemplo (BAUMAN, 1986; THORNBORROW; COATES, 2005; COUPLAND, et al., 2005; MOITA LOPES, 2006, 2009) sobre a narrativa. Portanto, consideramos o contar histórias como um lugar situado de conhecer ou saber mais sobre a vida social e sobre os " [...] efeitos discursivos que o ato de contar uma história provoca notadamente na construção de identidades sociais, subjetividades ou sociabilidades." (MOITA LOPES, 2010).

7 Ver Munanga (1986) e Wilchins (2004) para mais informações sobre tais características.

8 " $[. .$.$] compreendemos, contudo, que os discursos essencialistas típicos dos Movimentos Negros são estratégicos$ e necessários em situações diversas como a de combate ao racismo ou frente aos discursos de igualdade social." (MELO; MOITA LOPES, 2013, p. 242). 
Como aporte teórico-metodológico, a narrativa é um importante instrumento para sabermos como os hábitos são negociados e de que forma a vida social é incorporada nas práticas, ou seja, nas performances estilizadas ${ }^{9}$ ou não (COUPLAND, 2007). Nessa perspectiva, as histórias contadas são práticas discursivo-sociais contextualizadas e reportáveis. Por assim o serem, neste artigo, tornamos visíveis histórias marginalizadas durante a modernidade, como aquelas contadas por mulheres negras e homens negros. Segundo Adichie (2009), uma escritora nigeriana, em uma palestra no TEDGlobal sobre contar histórias, há vários exemplos de narrativas hegemônicas e descontextualizadas. Os problemas ocasionados por tais histórias é que, ao se narrar a história do outro por um único viés, e desconsiderando o contexto local, temos a criação de estereótipos. Eles são, para a autora, incompletos e transformam uma história em a única história, cujos efeitos semânticos homogeneizadores são percebidos nas diversas performances discursivas que encenamos todos os dias.

Neste estudo, a linguagem é entendida na perspectiva de Austin (1990) e Derrida (1988) como ação no mundo social, ou seja, ao enunciarmos nossas histórias, estamos, também, agindo nas práticas sociais. Pela iterabilidade e pelo caráter performativo dos atos de fala, esses enunciados são repetidos e constituem os corpos nas práticas sociais. Por meio da linguagem, compreendida como ação no mundo ou performance, agimos nas práticas sociais e podemos nos reinventar (PENNYCOOK, 2007). Seguindo essa linha de raciocínio, chama-nos atenção também o viés adotado por Bauman (1986), Threadgold (2005), Thornborrow e Coates (2005) e Moita Lopes $(2006,2009)$ de compreenderem a narrativa como performance.

Segundo Bauman (1986, p. 03), ao abordar as narrativas orais, a performance é entendida como

[...] um modo de comunicação, uma forma de falar e sua essência consiste em entender que temos uma responsabilidade para com os ouvintes, demonstrando nossa habilidade comunicativa, realçando, assim, o modo como a comunicação é concretizada com sucesso, independentemente do contexto referencial.

Já Goffman (2004, p. 61) faz uso do termo "performance" para designar toda a atividade de um indivíduo que ocorre durante um certo período ou momento, marcada pela presença contínua de outros que podem influenciar a performance projetada. Assim, a performance é para o outro, além de única, contextualizada, local e planejada. Compreendemos aqui o termo planejado mencionado por

\footnotetext{
Segundo Coupland (2007), há dois tipos de performances: as mundanas e as intensificadas. As primeiras são as performances comuns e as segundas são as exageradas ou teatrais. As últimas são planejadas, programadas e pré-anunciadas. Um exemplo dessas seria as performances de humoristas que se vestem de travestis em programas de TV, por exemplo.
} 
Goffman (2004) como o artístico de Bauman (1986), ou seja, o performer tem sempre a possibilidade de criar e de estilizar suas performances. Nas palavras de Pennycook (2010, p. 38), a criatividade seria " [...] uma forma divergente do senso comum", um recontextualizar o que já foi dito, um tornar novo o que já foi repetido.

Compreender a narrativa como performance, perspectiva adotada por Bauman (1986), Threadgold (2005), Thornborrow e Coates (2005) e Moita Lopes (2006, 2009), é entender que o narrador, ao contar sua história, está envolvido na encenação da performance no momento de narrar ou na experiência de relatar a história (THORNBORROW; COATES, 2005). Segundo tais autores, envolver-se em uma performance identitária que a narrativa encena para alguém ou por alguém reflete a natureza co-construída da linguagem. Em outras palavras, a narrativa como performance é um ato performativo, em que sujeitos sociais podem ser reinventados e modificados; por meio dela, as práticas e normas sociais podem ser transformadas, já que é uma performance discursiva ou um fazer pela linguagem. Os participantes estariam, então, construindo a vida social ao focalizar certas histórias, optar por alguns posicionamentos interacionais e ao interagir com outros na performance. Parafraseando Moita Lopes (2009, p. 135) em relação à questão racial podemos dizer que

[...] essa visão implica, portanto, que as performances narrativas podem ser compreendidas como lugares em que [o que se entende, no senso comum, como raças] também como performances são construídas nos embates pelo significado entre contadores, ouvintes e leitores.

Ancorados em Bauman e Briggs (1990), entendemos que as histórias que contamos podem ser entextualizadas. ${ }^{10}$ Tais processos as tornam sempre originais (THREADGOLD, 2005). Ao se recontar uma história, muda-se a situação, o contexto, a plateia e a própria história (THORNBORROW; COATES, 2005), o que torna cada narrativa única. Um exemplo disso está no blog objeto desta pesquisa, pois ao contar sua descoberta como mulher preta, apesar das semelhanças com outras narrativas de negras, a participante ao entextualizar sua pequena história, a torna única, local e original. Para a comunidade negra, tal narrativa pode significar, segundo Coupland et al. (2005), um repositório de material cultural rico para os membros usarem e reusarem; ao contar sua história, a participante se tornaria parte importante da prática que constitui a comunidade e o discurso. Nessa linha de raciocínio, pode-se dizer que a narrativa da blogueira está permeada por textos ou discursos de outros sujeitos sociais que influenciaram sua história (VOLOSHINOV, 1981). Seu reconhecimento como negra pode propiciar uma identificação da comunidade, justamente por encenar performances discursivas

10 Segundo Bauman e Briggs (1990), podemos compreender entextualização como a capacidade reflexiva do discurso de ser compartilhado em todos os sistemas de significação. Em outras palavras, a entextualização seria o enquadramento do texto em outros espaços, mas que carrega suas marcas históricas e sociais. 
permeadas por atos de fala performativos que as participantes da comunidade compartilham, como os de negritude, por exemplo.

Há dois aspectos para os quais os estudos de narrativa têm chamado atenção: o tempo narrativo e o ponto de virada (MISHLER, 2002). Quanto ao primeiro, tempo narrativo, as histórias contadas podem ser entextualizadas (BAUMAN; BRIGGS, 1990) em um tempo diferente do cronológico, que não necessariamente segue a ordem linear do tempo cronológico. Segundo Moita Lopes (no prelo), que ecoa Mishler (2002), os participantes de uma prática narrativa podem contá-la ou interpretá-la "[...] para além do tempo cronológico, refletindo sobre o que passou e dando outros fins para as narrativas e possibilitando, portanto, que sejam revisadas, com base em finais que já conhecem". Já o ponto de virada é um construto que, segundo Mishler (2002), está ligado ao momento em que os narradores realinham o sentido de final e o reinterpretam.

Outro aspecto importante ao se considerar a narrativa como performance é que, como tal, ela possibilita um quadro, segundo Bauman e Briggs (1990), que nos convida a uma reflexão crítica sobre os processos comunicativos. Além disso, os estudos da performance colocariam em questão as concepções dominantes de raça oriundas do Ocidente ou os efeitos semânticos da Modernidade nas práticas sociais marcados também nos corpos. Sendo assim, conceber as narrativas como performances locais é poder quebrar com os paradigmas das grandes narrativas e descobertas, desconstruir dicotomias e binarismos, ou seja, desafiar, queerizar as verdades cristalizadas e dolorosas vivenciadas por muitos sujeitos sociais, incluindo as mulheres negras. A visão de narrativa como performance nos propicia compreender as histórias como atos performativos, como práticas sociais contextualizadas, que possibilitam conhecer, desconstruir e reinventar a vida e as normas sociais, como nos mostra a história de Preta a seguir.

\section{Metodologia, contexto de pesquisa e construtos teóricos-analíticos}

Para atender às demandas da vida atual permeada pelas TICs, concordarmos com Hines $(2000,2005)$ e Guimarães $(2005)$ que a etnografia precisa ser repensada e adaptada para contextos outros, como por exemplo, o ambiente on-line. Dentro desse prisma, a etnografia virtual, na perspectiva de Hines (2000), nos permitiria pesquisar as experiências vivenciadas no mundo on-line ou entender como ocorrem as interações, mediadas pelas TICs (HINES, 2005). Nesta investigação, por exemplo, um dos pesquisadores participou do blog durante seis meses, acompanhando as postagens da blogueira, os comentários de seguidores, assistindo aos vídeos, ouvindo as músicas e lendo as diversas narrativas inseridas por Preta e/ou colaboradores, caracterizando, assim, este estudo como de caráter etnográfico virtual. 
Nesse tipo de etnografia, as noções de presença, espaço e temporalidade são transportados para o virtual, constituindo, assim, novas práticas sociais e interações que também nos possibilitam compreender pelas histórias locais o mundo on/off-line. Com base nesses aspectos, nesta pesquisa, interessam-nos as "pequenas histórias", pois, por meio delas, podemos trazer à visibilidade histórias que ainda se encontram à margem, compreender como os sujeitos sociais se posicionam nas narrativas que encenam e como eles apresentam o mundo em que vivem (BAMBERG; GEORGAKOPOULOU, 2008; BAMBERG, 2011).

Os dados deste trabalho foram gerados no blog "Eu, Mulher Preta", que constituiu um corpus composto por um conjunto de narrativas autobiográficas, ${ }^{11}$ produzidas pela autora do blog e postada às 12h23min, em 29 de novembro de 2009. Optamos pela história intitulada "Tornando-se preta num segundo nascimento", porque ela relata o renascimento da blogueira como mulher negra. Entendemos que, seguindo Wortham (2001, p. 11), contar sua própria história pode, algumas vezes, transformar o eu do narrador, recriá-lo ou reforçá-lo. Para o estudioso, a narrativa autobiográfica "[...] faz mais que descrever um eu preexistente", algumas vezes, o ato de narrar sua própria história pode mudar quem o narrador é.

Para a análise dos posicionamentos interacionais e das performances narrativas, embasamo-nos no conceito de posicionamento interacional, que também é utilizado em outras áreas de conhecimento como a antropologia, a psicologia social etc. (MOITA LOPES, 2009). Neste estudo, a perspectiva de posicionamento interacional é aquela proposta por Wortham (2001), que o utiliza para analisar autobiografias, caso deste estudo. Para o autor, o posicionamento é compreendido como um construto teórico, que dá conta de como o narrador e a audiência, quando em processo de interação, assumem o "papel" de alguém naquela posição. Em outras palavras, narrador e audiência encenam performances identitárias de acordo com o posicionamento interacional que ocupam e o ato de contar uma história pode posicionar audiência e narrador de várias maneiras. Neste estudo, interessa-nos, especificamente, o posicionamento interacional da narradora em relação à sua audiência projetada, discutido seguir.

Ainda sobre a análise, fazemos uso das seguintes pistas indexicais listadas por Wortham (2001) para sinalizar as interpretações que fazemos dos posicionamentos interacionais na construção de sentidos emergentes na performance narrativa: referência: são elementos do mundo ao qual o narrador se refere; predicação: é a caracterização de elementos mencionados pelo narrador; citação: está relacionada à citação da fala do outro para recriar um momento da interação; e índices avaliativos: são itens lexicais, construções gramaticais, sotaque etc. que caracterizam socialmente grupos sociais ou sujeitos sociais.

11 Até a finalização deste artigo havia cerca de 81 postagens no blog de vídeos, entrevistas e narrativas. 
Além das categorias citadas, consideramos ainda as modalizações lógicas (epistêmicas) e as deônticas. A primeira, segundo Machado (2009), exprimem o grau de verdade indicada pelas unidades linguísticas que avaliam o conteúdo temático ou, nas palavras de Bronckart (2007), indicam os julgamentos de valor e de verdade. Já as modalizações deônticas, conforme Bronckart (2007), estão relacionadas ao valor social; aos fatos narrados que são apresentados como socialmente permitidos, desejáveis, necessários, obrigatórios etc.

Nesta investigação, optamos pelo blog, porque é isento de custo e restrições e tem sido usado como um diário pessoal, em que sujeitos sociais diversos contam suas histórias, compartilham imagens, vídeos e áudios relevantes para as performances narrativas contadas nesse espaço. É isso que Preta faz em seu blog, que visa a "[...] trocar experiências e discutir sobre as questões raciais e de gênero e tantos os tipos de discriminação existentes nessa sociedade de opressores e oprimidos [...]" (PRETA, 2009). Com base nesse objetivo, nas imagens de pano de fundo, nas figuras presentes em suas narrativas, no layout do blog, nos vídeos, nas músicas e nos textos, a audiência projetada desse blog pode ser compreendida como sujeitos sociais interessados em discutir questões de raça e gênero, mulheres e homens negros ou não negros que se interessem pela temática proposta por Preta, uma paulistana que se descobriu negra depois dos 20 anos. Vale salientar, no entanto, que há uma predominância de temas abordados por Preta e parceiros que poderiam interessar mais às mulheres negras.

\section{As duas performances de Preta no tempo narrativo}

Esta análise é construída por duas performances narrativas distintas de Preta, uma de mulher preta e outra de mulher branca. Como mencionado anteriormente, a performance narrativa analisada é intitulada "Tornando-se preta num segundo nascimento", por Preta, um pseudônimo da narradora paulistana identificado em todo o blog. O título nos indica que a autora não se constituía como negra e, quando se percebe como tal, ela entende esse processo como um segundo nascimento e o relata em seu blog. Esse posicionamento interacional de mulher preta, para sua audiência projetada interessada em discutir questões de raça e gênero, é indexicalizado por predicação e referência pelos índices lexicais: "tornando-se preta" e "segundo nascimento", no título.

Nessa narrativa, os recursos semióticos de um texto multimodal ${ }^{12}$ (KRESS; VAN LEEUWEN, 1996) colaboram na construção dos sentidos mobilizados, ajudando a

12 Os recursos multimodais empregados em todo o blog enfatizam o título do blog "Eu, Mulher Preta" e o pseudônimo da blogueira, Preta. Além disso, eles também marcam e intensificam o seu posicionamento interacional como mulher preta e a encenação de suas performances discursivas de aproximação e valorização dos(as) negro(as), projetadas ao longo da narrativa em análise. Assim, observamos que a narradora faz uso da 
posicionar a narradora interacionalmente antes e depois de sua reinvenção como mulher negra, para sua audiência, negras(os) e não negras(os), o que também refletirá em suas performances narrativas de mulher "morena não tão clara" e de mulher preta, como veremos ao longo da análise.

O narrar de Preta segue o tempo narrativo (MISHLER, 2002), o que possibilita a blogueira revisar os eventos que viveu, retomá-los e recontá-los para além do tempo cronológico, ou seja, no momento que vivencia agora. O ponto de virada, nessa história (MISHLER, 2002), ocorre quando a narradora se percebe constituída como mulher negra e militante. Ela, então, realinha sua história, a reinterpreta de outra forma a partir dos 20 anos, consegue relatar sua transformação, suas dores e indicar seu posicionamento interacional antes de seu renascimento como negra. Ao narrar, Preta apresenta um posicionamento interacional de aproximação e valorização da negritude. Contudo, ao relatar alguns fatos de sua vivência ao longo da vida, ela indica que já assumiu um posicionamento de distanciamento da negritude. Tais posicionamentos refletiram e refletem nas duas performances narrativas antagônicas encenadas: uma como mulher que busca se afastar do fato de ser negra e outra que tenta se aproximar da negritude, ou seja, na primeira, ela se constituía como mulher "branc[a] meio suj[a]" e na segunda como "mulher preta".

Na história contada por Preta, foco desta análise, o ponto de virada, indexicalizado desde o próprio título ("tornando-se preta" e "segundo nascimento"), é identificado quando ela se percebe constituída como mulher preta após os 20 anos e se posiciona interacionalmente como mulher negra em relação à sua audiência projetada em toda a narrativa. Assim, ela realinha sua história e recupera, pelo tempo narrativo, seu posicionamento interacional anterior ao seu renascimento como negra. A partir de todo esse realinhamento, a narradora passa a contar suas dores, suas estratégias de sobrevivência, suas experiências com o racismo etc., ou seja, ela encena duas performances narrativas: uma de mulher branca meio suja e outra de mulher preta, como veremos a seguir.

\section{Performance narrativa de mulher "branc[a] meio suj[a]"}

Nessa performance discursiva que se aproxima da mulher branca, a narradora se posiciona interacionalmente de modo que se distancia da negritude, faz uso de índices linguísticos (verbos "olhava", "enxergava-me", "via" e "ajudava" no pretérito imperfeito) para sinalizar uma ação inacabada, colocando-se na posição de narradora:

natureza multimodal do blog para, por exemplo, cristalizar a negritude como a única possibilidade de ser mulher preta, enfatizando, assim, a dicotomia mulher branca versus mulher negra, aspectos também observados na análise. Embora a multimodalidade seja um elemento constitutivo do blog, por razões de espaço, optamos por não perseguir a análise multimodal. Ver, no entanto, Moita Lopes (2009). 
Quando me olhava no espelho não me via como me vejo hoje. Enxergavame como gostaria de ser: de um branco meio sujo, uma morena não tão clara, morena escura talvez!? O cabelo alisado me ajudava no processo de alienação. Afinal, pelo menos os meus cabelos estariam no padrão.

A modalização deôntica ("gostaria de ser" e "estariam no padrão") pode indicar um desejo da narradora de pertencer à outra raça. Pelo uso de predicações ("branco meio sujo", "morena não tão clara" e "morena escura"), Preta indexicaliza uma performance identitária de mulher branca e ao mesmo tempo de negação de sua cor da pele (negra) ao buscar clareá-la. O "cabelo alisado", outra predicação, também marcaria a constituição de Preta como branca, visto que ela compreende esse tipo de cabelo como parte de um processo de alienação do qual ela fazia parte, desconsiderando, assim, como propõe Costa de Paula (2010, p. 276) “[...] que alisar é uma questão de beleza e não uma negação da raça." Pela predicação empregada em sua narrativa, Preta se posiciona de forma distante do corpo ébano que a marca. No trecho seguinte:

Queria ter nascido uma parda como são consideradas as minhas irmãs (afinal, antes um branco meio sujo do que do que preto ou preta: sujo, encardido, triste, perigoso, assustador, nefasto, escravo, individuo da raça negra...). Queria os olhos azuis ou verdes, queria o cabelo liso ou ondulado, queria a pele branca, rosada ou bronzeada do sol, o nariz fino e arrebitado...

A narradora encena uma performance narrativa de distanciamento de negritude caracterizado por meio da predicação ("branco meio sujo"). Ela ainda introduz as irmãs como personagens que admira e com quem gostaria de parecer, enfatizando o desejo de pertencer à outra raça pela modalidade deôntica ("queria ter nascido uma parda como são consideradas as minhas irmãs, afinal antes um branco meio sujo do que preto ou preta"). Com base no trecho citado anteriormente, observamos ainda que por meio de índices avaliativos, a predicação ao negro é indexicalizada negativamente ("sujo", "perigoso", "assustador", "encardido", "escravo", "nefasto"). Descrições negativas semelhantes eram percebidas na literatura chamada de Ciência da Raça (MUNANGA, 1986) para caracterizar a população negra. Observamos também a dicotomia criada por Preta na narrativa de mulher branca versus mulher negra, sendo que a primeira, indexicalizada em contraste com a segunda, é qualificada positivamente por predicação e referência ("olhos azuis ou verdes", "cabelo liso ou ondulado", "pele branca, rosada ou bronzeada do sol", "o nariz fino e arrebitado"). A repetição da modalização deôntica ("queria os olhos azuis ou verdes, queria [...]") enfatiza o desejo de ser branca da narradora.

Nessa parte da narrativa, a blogueira consegue retratar seu posicionamento interacional de distanciamento da negritude para sua audiência, quando se 
percebe como mulher preta, ou seja, após aceitar-se, constituir-se ou renascer como tal mulher. Em outras palavras, o tempo narrativo e o ponto de virada (MISHLER, 2002) possibilitam que a narradora retome sua história e conte que, no passado, assumiu posicionamentos interacionais que constituíram suas performances discursivas encenadas como "branc[a] meio suj[a] ou morena clara".

\section{Performance narrativa de mulher preta}

O ponto de virada (MISHLER, 2002) na performance narrativa, sinalizado inicialmente pelo título da narrativa, depois ao longo da narrativa por predicação, referência, índices avaliativos e modalidade lógica, permite que Preta critique seu posicionamento de distanciamento da negritude e sua performance discursiva de "branc[a] meio suj[a]". Assim, a narradora também identifica momentos de dor vivenciados ao longo de sua vida, justifica sua performance discursiva de mulher branca e encena performances essencializadas de mulher preta e militante. Observamos aqui que Preta reitera o posicionamento interacional de aproximação e valorização da negritude predominante em toda a narrativa

Nesse processo em que se co-constrói como mulher negra, Preta relata como isso tem início após os 20 anos. A narradora encena performance de mulher negra ao se identificar como preta, recorrendo à cor e não à raça para se marcar como mulher de luta, de militância e engajada nos movimentos sociais em defesa das pessoas negras. O termo "preto" ou "preta" é repetido e retomado durante toda a narrativa, enquanto o item lexical "negro" é evitado. Isso nos remete à terminologia dos movimentos sociais citados que buscam ressignificar o termo "preto"/"preta", compreendidos negativamente ao longo dos séculos na sociedade, como observado por um dos pesquisadores que participa de movimentos sociais de valorização das raças negras.

Na narrativa, o fato de a blogueira se perceber como mulher preta após os 20 anos é compreendido por ela como algo muito desconfortável. Isso é perceptível, porque ela menciona tal aspecto em momentos distintos em sua performance:

Eu por exemplo tenho 25 anos, mas apenas há 5 anos enxergo-me enquanto preta. (PRETA, 2009, grifo nosso).

A modalização lógica ("eu por exemplo tenho 25 anos, mas apenas há 5 anos enxergo-me enquanto preta") e o índice avaliativo ("mas apenas") indexicalizam o desconforto de Preta em descobrir-se negra após os 20 anos e é também um julgamento de valor ao seu renascimento tardio. A performance discursiva como negra é indexicalizada por meio de elementos de referência e de predicação. Os índices linguísticos ("tenho", "enxergo", "é", "sou", "alisa", verbos no presente do 
indicativo), observados no exemplo citado anteriormente e também no seguinte, marcam uma ação habitual de como a narradora se percebe após o renascimento:

Não é simples passar a aceitar-se. Escurecer sua pele dizendo: "Não sou morena, sou preta", livrar-se da química tão impregnada no seu cabelo, adotar um black, uma trança, o cabelo natural de uma mulher preta. Estar preparada para os olhares, para os comentários: "Nossa porque você não alisa esse cabelo?", "Eu não teria essa coragem de deixar meu cabelo assim", "Preta? Mas você é moreninha. Falar preta é feio...". (PRETA, 2009, grifo nosso).

Os verbos no infinitivo ("livrar-se", "passar", "aceitar-se", "escurecer-se", "adotar", "estar", "deixar" e "falar") indexicalizam os processos vivenciados pela narradora antes de seu renascimento como mulher preta. Ainda ressaltamos o uso de citação em discurso direto, trazendo os questionamentos de outros à blogueira ao se posicionar como mulher preta, ao passo que tal discurso indica a modalização lógica e fornece verossimilhança à história que relata. Vale salientar que por meio da citação, a narradora entextualiza os discursos de outros sobre seu corpo ébano, ouvidos ao longo de sua vida.

Esse mesmo desconforto é repetido em outros trechos ao longo da narrativa:

É estranho como podemos passar uma vida inteira sem nos enxergarmos como realmente somos. Como pode (perguntarão alguns) alguém não perceber que nasceu com a pela escura, com o cabelo crespo, com o nariz largo, enfim... Como pode alguém não perceber que nasceu preto ou preta? E eu respondo: isso é totalmente aceitável nessa sociedade racista.

Nasci: Agora sim uma mulher preta! E como foi estranho me olhar no espelho pela primeira vez, sem o véu da alienação... Uma imagem estranha refletia no espelho. Senti-me como um cego a enxergar pela primeira vez: - Então eu sou assim?

Esse constrangimento em ter-se compreendido como preta tardiamente é marcado, dessa vez, pelos índices avaliativos introduzidos pela pergunta ("como pode (perguntarão alguns) alguém não perceber que nasceu com a pela escura [...]?"), por meio de predicação ("estranho", "cego", "véu de alienação") e pelo índice avaliativo ("então eu sou assim?"). Esse posicionamento interacional de aproximação e valorização da negritude colabora na encenação da performance identitária de Preta como uma mulher preta.

As características físicas são atributos trazidos bela blogueira para adjetivar seu corpo. Elas são sinalizadas pelas predicações ("a pele escura", "os cabelos crespos", "sem química no cabelo" e "o nariz largo"). Segundo Costa de Paula (2010), o cabelo crespo versus cabelo liso, assim como as outras características físicas, sustentaria a lógica dicotômica racial que caracteriza a mulher negra entre 
aquelas que assumem sua negritude e as que embranquecem. Sendo assim, são apagadas as diversas outras possibilidades de ser negras.

Essa caracterização essencialista trazida por Preta pode mostrar seu processo de desconstrução de mulher branca "meio suja, encardida" e de coconstrução de mulher negra, propiciados pelo ponto de virada da narrativa. Com base em Wilchins (2004), podemos dizer que Preta não estava apenas encenando performances narrativas de mulher preta, ela estaria também aprendendo a ser negra. Contudo, embasados nas Teorias Queer, observamos aqui uma normalização imposta ao corpo ébano das mulheres negras, desconsiderando outras possibilidades de tais mulheres se constituírem fisicamente, apagando, também, as mulheres que já têm seus corpos constituídos diferentemente do padrão trazido pela blogueira. Além disso, a essencialização da raça negra por meio de características físicas específicas contraria as propostas das Teorias Queer de compreender as subjetividades raciais como perpassadas por gênero, sexualidade, classe social etc. (SOMMERVILLE, 2000; BARNARD, 2004; WILCHINS, 2004).

Para justificar as performances identitárias de mulher branca e distanciar-se do fardo de ser uma mulher negra, Preta entextualiza, por meio de referência e de predicação ("barbies magras, de pele clara, olhos azuis, cabelos longos e lisos"), discursos da mídia que colocariam as mulheres brancas em uma posição de destaque.

Cresci num mundo de apresentadoras infantis loiras, de barbies (magras, de pele clara, olhos azuis, cabelos longos e lisos), de "contos de fadas" sem nenhuma princesa preta. Desenhos, revista, livros, televisão... Tudo, mostrando-me o quanto era ruim nascer preto ou preta.

No processo de co-construção como mulher preta, a narradora também aborda alguns sentimentos vivenciados ao longo do seu reconhecimento e inclui uma nova personagem, a mãe, que lhe despertava raiva:

Raiva: da pele escura, do cabelo crespo, do nariz, da boca, do quadril largo, das características herdadas dos nossos pais. Por que nascer desse jeito?

Passamos a nos odiar, odiar quem amamos e todos/as aqueles/as que são parecidos/as com a gente.

Durante muito tempo odiei as pessoas erradas. Olhava para minha mãe e sentia raiva dela, por ter saído como ela.

Os sentimentos de raiva e ódio são indexicalizados por meio de índices de referência e de predicação ("raiva", "do cabelo crespo", "da pele escura", "do quadril largo", "das características herdadas dos nossos pais") e pela avaliação ("por que nascer desse jeito?"). Observamos que as repetições tanto paralelísticas 
("do cabelo", "da pele", "do quadril") como também dos itens lexicais "odiar" e "odiei" reforçam as marcas corporais que constituem Preta como negra e indicam o alto grau de rejeição de tais marcas por parte da blogueira antes de seu renascimento.

Momentos de dor também vivenciados por Preta desde a infância são mencionados pela narradora:

Ao entrar na escola percebi a dor cruel do racismo. Só quem é preto ou preta vai entender o significado de um apelido na escola (negrinha fedida, cabelo Bombril, macaca, safada...). Saber que você é xingada por conta da cor da sua pele.

Um deles é a consciência do racismo, cujo contato primeiro ocorreu na escola, como apontado anteriormente. Esse contato é sinalizado pela predicação ("negrinha fedida, cabelo Bombril, macaca, safada"). Ainda sobre a discriminação racial, a blogueira pontua que:

A dor do racismo é uma ferida que só dói quando a tocamos. Por isso é fácil entender por que muitos preferem não falar sobre o que sofre. Como é dolorido "o despertar". Sair dessa alienação é passar pelo processo do parto, nascer novamente. E foi isso que aconteceu comigo.

Nesse processo de co-construção de Preta como mulher negra e militante, ela retoma os discursos racistas e das grandes narrativas que silenciam negras(os). A narradora relata os efeitos semânticos de tais discursos em sua vivência, sinalizados pelos índices de referência e de predicação ("dor", "ferida", "dói", "sofre", "dolorido", "processo do parto") que enfatizam sua dor particular e sua intensidade. Além disso, podemos hipotetizar que ecoam também a dor de outros negros e outras negras que tiveram experiências semelhantes e o motivo para se silenciarem.

Esses xingamentos repetidos dentro e fora da sala de aula são atos de fala performativos que marcam os vários corpos ébanos ao longo de suas vidas e são assimilados por muitos negros e negras, desde a infância, que se co-constroem ou se constituem por tais discursos que escravizam. Outro ponto que deve ser abordado na análise são as estratégias de reação ao racismo:

No começo buscamos o auxílio da professora. E essa, muitas vezes não julga o racismo sofrido por uma criança algo relevante.

Posicionando-se interacionalmente como preta à sua audiência projetada, a narradora, por meio de índices avaliativos ("não", "julga", "sofrido", "muitas vezes") e de predicação ("relevante") encena performances identitárias estratégicas para reagir às práticas racistas. Uma delas é a busca pelo auxílio da professora, 
personagem que não sabia lidar com a situação indicada, o que reforça o despreparo de alguns docentes em desconstruir discursos racistas em sala de aula, como já indicado.

Além de retomar suas dores, a narradora cita a importância de se criar estratégias para lidar com as decepções visto que o mundo segue em frente. Preta entextualiza aqui uma frase encontrada na internet e atribuída a William Shakespeare. ${ }^{13}$ Isso ocorre pelo uso de citação e modalização lógica indicando uma verdade e um julgamento ("Não importa em quantos pedaços seu coração tenha se partido, o mundo não parará para que você o concerte"):

Com isso percebemos, decepcionados, que: "Não importa em quantos pedaços seu coração tenha se partido, o mundo não parará para que você o concerte". E dessa forma aprendemos que estamos sozinhos/as nessa luta e que precisaremos criar estratégias de defesa para sobreviver nessa sociedade que nos exclui.

Aprendemos a nos tornarmos invisíveis: Sempre calados, de cabeça baixa, olhos para o chão, o corpo numa tentativa desesperadora de entrar em si mesmo encolhe-se, encurva-se, tornar-se nosso refúgio e também nosso castigo.

Outra performance discursiva estratégica para sobreviver ao racismo e ao despreparo de docentes na escola, por exemplo, é encenar performances narrativas de invisibilidade. As pistas linguísticas ("estamos sozinho", "exclui") indexicalizam tal performance. Essa invisibilidade, ainda, é predicada antagonicamente ("refúgio" e "castigo") e por meio de referência a toda uma performance corporal ("cabeça baixa", "olhos para o chão", "encolhe-se") para descrever o corpo ébano invisível.

Considerando Bauman (1986), Threadgold (2005), Thornborrow e Coates (2005) e Moita Lopes (2006, 2009), podemos dizer que a blogueira, mantendo seu posicionamento interacional de mulher preta, se envolve na performance de mulher preta e se aproxima ainda mais de sua audiência projetada ${ }^{14}$ ao incluí-la explicitamente ao longo da narrativa por referência ("nós", como sujeito oculto, e pronomes possessivos "nosso" e "nossa"):

Dessa forma vamos mutilando nosso corpo, nossa alma, nosso psicológico. Assimilando cada vez mais as características do opressor, a política do opressor, a cultura do opressor... Um desejo de quem sabe um dia torna-se a cópia do opressor.

13 Essa citação de William Shakespeare pode ser encontrada em: <http://pensador.uol.com.br/frase/NjkxMDA/>

14 Os comentários dos seguidores do blog ratificam tanto o posicionamento interacional de proximidade à negritude, bem como as performances discursivas de Preta ao longo da narrativa. Vale salientar que tais comentários não são foco desta investigação, já que a autorização para a pesquisa foi somente para os textos da blogueira. 
Para essa audiência que pode ter vivido experiências próximas à de Preta, ela relata como os discursos de preconceito, de discriminação racial e do racismo afetam os corpos negros, ou melhor, como os efeitos semânticos de tais discursos podem afetar os corpos ébanos. Alguns índices de referência e de predicação ("opressor", "política do opressor", "cultura do opressor" , "mutilando nosso corpo, nossa alma, nosso psicológico") empregados por Preta podem aproximá-la ainda mais de uma parte de sua audiência, especificamente àquela conhecedora ou participante de movimentos sociais em defesa do negro. A narradora recorre a uma terminologia e significados recorrentes em nossa sociedade voltados, especificamente, para aqueles que participam de movimentos sociais em defesa do homem negro ou da mulher negra, experiência vivenciada por um dos autores desta investigação aqui relatada.

Enquanto seu posicionamento interacional próximo à negritude enfatiza sua performance discursiva de mulher negra e militante, Preta questiona os discursos de objeto sexual a que negras são expostas,

[...] queria estar no padrão, ser olhada e admirada e não tratada como pedaço de carne, como aquela que é boa como amante (afinal, as negras são historicamente boas de cama, boas amantes, desde da época da escravidão quando eram estupradas pelos seus senhores).

Ela recrimina as performances discursivas desde a escravidão, que transformaram mulheres negras em objetos sexuais. Isto pode ser percebido pela predicação ("boas de cama", "boas como amante", "boas amantes" ou "pedaço de carne"). A narradora, por meio da modalização deôntica ("queria estar no padrão, ser olhada e admirada"), sinaliza que desejaria ser tratada de forma diferente das negras vistas como objeto sexual.

Na narrativa de Preta, ela entextualiza discursos familiares a muitos negros e propagados pelos discursos de democracia racial, de que o negro é aquele que vê racismo em tudo, indicando que ele seria racista por abordar a questão racial. Isso pode ser percebido pela modalidade lógica, sinalizando um julgamento, e pela citação ("Às vezes escuto pessoas dizerem: "'Vocês negros é que vêem racismo em tudo"'):

Às vezes escuto pessoas dizerem: "Vocês negros é que vêem racismo em tudo". Hoje ao ouvir esse tipo de comentário respondo com a maior naturalidade: Sim, Eu que vejo racismo em tudo, afinal sou eu que sofro racismo todo o dia quando saio na rua, quando entro numa loja e a vendedora gruda em mim, quando vou a um salão qualquer e escuto a cabeleireira dizer que vai "dar um jeito no meu cabelo" como se meu cabelo já não fosse ajeitado com jeito crespo dele.

A blogueira se posiciona contrária ao comentário, enfatizando o racismo que sofre cotidianamente pelo fato de ela ser negra e viver tais experiências. A 
modalização lógica ("afinal sou eu quem sofro racismo todo dia quando saio na rua, quando entro numa loja e a vendedora gruda em mim, quando vou a um salão") traz veracidade à performance da narradora. Por outro lado, observamos uma desqualificação do discurso de não negros que desconheceriam ou seriam menos sensibilizados às performances discursivas de discriminação sofridas por negras(os)

Apesar de marcar seu posicionamento de militante por toda a narrativa, ele se torna mais explícito quando Preta aborda a questão específica dessa militância. Tal aspecto é destacado pelo índice avaliativo ("jamais"), indicando impossibilidade; pela modalização deôntica ("enquanto mulher preta jamais poderei deixar de militar"), sinalizando uma obrigação, e pelos índices lexicais ("debater", "lutarmos", "revoltar-nos"):

Enquanto mulher preta eu jamais poderei deixar de militar e debater sobre o racismo, pois esse baterá na minha porta todas as manhãs. Uma vez que saímos da caverna, que percebemos que a imagem projetada no fundo da caverna não era a realidade verdadeira, estamos condenados à dor da indignação, a revoltar-nos com as desigualdades dos nossos irmãos e irmãs, a lutarmos em nome de tantos outros/as que lutaram no passado.

Ser preto ou preta é descobrir sua história, entender as lutas e as injustiças do passado, reafirmar sua identidade no presente, visando o futuro das novas gerações que muito ainda terão que lutar.

Além disso, a blogueira se aproxima da negritude ao se posicionar como militante, encenar performances de mulher preta e conceber o que é ser preta, observadas por meio de modalizações lógicas ("ser preto ou preta é descobrir sua história, entender as lutas e as injustiças do passado, reafirmar sua identidade no presente [...]"). A narradora enfatiza nesse momento do seu narrar uma única possibilidade de se co-construir como negra, apagando novamente outras possibilidades.

Nessa performance narrativa, percebemos que a raça é o foco central da história de Preta. Com base na análise, podemos dizer que o posicionamento interacional da blogueira de aproximação e valorização da negritude reflete em suas performances discursivas de mulher negra encenadas ao longo da narrativa. Assim, ela faz uso de referência, predicação, citação, índices avaliativos, modalizadores lógicos e deônticos indicados ao longo deste estudo. Na análise da narrativa, observamos uma série de entextualizações de discursos de raça que permeiam a sociedade na encenação de suas performances narrativas de mulher preta.

Ademais, observamos em toda a narrativa que a blogueira, pelo emprego e repetição do próprio termo "preta", parece ressignificá-lo, atribuindo-lhe sentidos 
positivos, como, por exemplo, o fato de pertencer a um grupo militante. Essa ressignificação nos remete ao ocorrido com o termo "queer", ${ }^{15}$ desconstruído pelas Teorias Queer.

Salientamos, ainda, que o essencialismo estratégico de raça observado ao longo da narrativa de Preta pode tê-la ajudado a renascer e se co-construir como mulher preta. Considerando as palavras deWilchins (2004), durante a performance narrativa, Preta indicava que estava aprendendo a ser de uma raça, ou seja, aprendendo a ser negra. Por outro lado, entendemos que essas normalizações cristalizam binarismos e não nos possibilitariam compreender a constituição do sujeito como híbrido, ou seja, perpassado e co-construído por outros traços performativos como gênero, classe social, grau de escolaridade e outros que os desessencializam. Vale dizer também que tais naturalizações apagam os outros sujeitos sociais negros, homens e mulheres, que não se encaixam no padrão observado na performance narrativa da blogueira.

\section{Considerações finais}

Embasados em Goffman (2004), podemos dizer que as performances narrativas de Preta designam as atividades individuais da narradora marcadas pela presença contínua de outros. De um lado, ela relata o renascimento da mulher negra que havia sido sufocada e supostamente influenciada por instituições como a mídia, a família, a escola e cujo desejo era encenar performances de uma "branc[a] meio suj[a]", que se distancia de tudo que a remeteria à negritude. Por outro lado, após o renascimento, observamos performances discursivas hegemônicas de negritude que também apresentam seus discursos marcados na pele escura, no quadril largo e no cabelo crespo. Apesar de ser possível dizer que a raça foi diluída no gênero, observamos na análise que se mantém a hegemonia da questão racial, o que, segundo Barnard (2004), não possibilitaria compreender a(o) negra(o), ou, no caso, Preta em sua plenitude, se não considerarmos gênero, raça, grau de escolaridade e outros traços performativos.

Percebemos, pela análise, que a blogueira recupera e entextualiza nas estruturas capilares de sua performance narrativa discursos hegemônicos, cristalizados e baseados na Ciência da Raça e/ou Democracia Racial sobre negras e negros, propagados há séculos na sociedade brasileira. Ao posicionar-se como mulher preta ou candace, a narradora se compreende como um sujeito social que se reinventa com base em um passado de mulher "branc[a] meio suj[a]".

15 O termo "queer", em inglês, significa "excêntrico", "estranho" e é utilizado pejorativamente para se referir a homoafetivos masculinos. No entanto, segundo Louro (2004, p. 38), ele foi ressignificado pelas Teorias Queer, como "colocar-se contra a normalização - venha ela de onde vier". 
Vale salientar que estamos situados em um momento sócio-histórico, no Brasil, em que os movimentos sociais buscam valorizar a negritude e o reconhecimento dela por negras(os), como nos mostra a história de Preta. Nesse sentido, pelo blog, uma mulher negra pôde encenar sua performance narrativa, exercer a cidadania e lutar por seus direitos, desconstruindo, assim, as verdades absolutas cristalizadas durante a Modernidade, em que muitas vozes foram apagadas (BAUMAN, 2001; VENN, 2000; SANTOS, 2008; RAMPTON, 2006). Além disso, a narrativa como performance de Preta é um instrumento relevante para conhecermos como a vida social é incorporada nas práticas (THREADGOLD, 2005). Por meio da pequena narrativa de Preta, podemos trazer à visibilidade histórias ainda marginalizadas e buscar entender como os sujeitos sociais se posicionam na narrativa e como eles apresentam o mundo em que vivem (BAMBERG; GEORGAKOPOULOU, 2008; BAMBERG, 2011).

Esta investigação nos mostra que, pelas novas possibilidades trazidas pela web 2.0, a blogueira é transgressora ao deixar de lado o silêncio imposto aos corpos ébanos na Modernidade, ao contar sua história de renascimento como mulher preta, reconhecer a dificuldade de se aceitar como mulher negra e observar os efeitos semânticos dos discursos da chamada Ciência da Raça e/ou Democracia Racial em seu próprio corpo, em seu posicionamento interacional em relação à sua audiência e na encenação de suas performances discursivas. Outro aspecto relevante é que Preta traz outra possibilidade de relatar sua história, desconstruindo os estereótipos negativos quanto à(o) negra(o), comparado aos discursos de Ciência da Raça e de Democracia Racial.

Por outro lado, observamos que esse reinventar-se está permeado por discursos essencialistas de negritude, pela sedimentação das velhas dicotomias e por um acirramento do binarismo mulher negra versus mulher branca, em que a primeira seria considerada inferior à segunda pela sociedade. Desse modo, a mulher preta precisaria assumir-se, militar e encorajar seus pares a "tirarem do armário", por assim dizer, sua identidade social de uma mulher negra específica. Essa mulher preta é compreendida, como a análise sugere, como a única possibilidade de ser ou a única história a ser contada. Temos aqui a criação de estereótipos, mencionada por Adichie (2009), que gera sofrimentos e sedimenta ainda mais as dicotomias raciais que as Teorias Queer buscam desnormalizar e desconstruir. Reconhecemos que tais discursos são importantes para as lutas políticas, mas são também excludentes visto que apagam as diversas possibilidades de subjetividades e reforçam os discursos binaristas, combatidos pelas vertentes Queer.

Observamos, como em Melo e Moita Lopes (2013), que simultaneamente a seu reconhecimento como mulher preta, há a cristalização de uma única possibilidade de se constituir como tal. A raça é valorizada como o único traço performativo. Mesmo quando mencionada a questão do gênero, essa está submetida à raça. 
Há uma sedimentação de discursos de valorização racial que impossibilita desnormalizar qualquer tipo de essência, seja de raça, gênero, sexualidade etc. Ao focar na questão racial de forma essencialista, deparamo-nos com o apagamento de diversos contextos em que negras(os) vivem no Brasil, aspecto prejudicial aos próprios corpos ébanos.

Este artigo, portanto, traz a questão racial como um traço performativo para o centro das discussões, tirando a raça da margem e colocando-a ao lado de gênero e sexualidade. Ademais, esta investigação também contribui para a compreensão de que, nas práticas sociais, os sujeitos sociais negros podem encenar outras performances narrativas sobre o que são ou estão sendo. Isso significa que as dicotomias hegemônicas de racialização precisam ser desnaturalizadas, porque ratificam os discursos de que a(o) negra(o) deve ficar no seu lugar. Em outras palavras, tais dicotomias continuam mantendo muitos sujeitos sociais de corpo ébano na invisibilidade e dentro de limites muito óbvios e claros sobre quem são ou podem ser, posição que vai de encontro a nossos interesses de luta por práticas sociais mais justas e éticas que, como tais, não devem admitir qualquer sofrimento humano.

\section{Agradecimentos}

Sou grata ao CNPq pela bolsa 159621/2010-0, no âmbito do Edital MEC/CAPES e MCT/CNPq/FINEP No 28/2010 - Programa Nacional de Pós-Doutorado - PNPD 2010, que possibilitou este estudo. Tal bolsa foi concedida ao Projeto "Letramentos Digitais Singularidades do Ethos, Performances e Narrativas Identitárias", do Prof. Dr. Luiz Paulo da Moita Lopes (CNPq 560303/2010-06).

Agradeço ao CNPq pela Bolsa de Produtividade que propiciou esta pesquisa (CNPq 3033-1/2009-0), assim como ao auxílio à pesquisa da FAPERJ (E -26/110.065/2012) e ao PNPD 2010 (MEC/CAPES e MCT/CNPq/FINEP - CNPq 560303/2010-06), referido anteriormente.

MELO, G. C. V. de; MOITA LOPES, L. P. da. A blogger's narrative performance: "becoming black, a second birth". Alfa, São Paulo, v.58, n.3, p.541-569, 2014.

- ABSTRACT: Web 2.0 provides social subjects with the possibility of telling their stories as well as with ways of having them discussed in new interactional forms. This article aims at presenting the interactional positionings which construct a black woman's narrative performance of race in the blog "Eu, Mulher Preta" (I, a Black Woman). This study is based on new digital literacy theories, views of race informed by Queer Theories and on the theorization of narrative as performance. To analyze the blogger's narrative as performance, the analytical framework is based on indexical clues, which indicate particular interactional positionings. The analysis draws attention to the teller who positions herself interactionally as a black woman. 
We identify, however, a different interactional positioning before her rebirth as black, that is, as a "dirty-white woman". These positionings reflect two conflicting narrative performances: one as black and another that distances herself from her racial origin. This investigation also makes it possible to view race, based on Queer Theories, as a performative trace, placing it side by side with gender and sexuality.

- KEYWORDS: Black woman. Queer theories. Blog. Narrative as discursive performance. Interactional positionings. Indexical clues.

\section{REFERÊNCIAS}

ADICHIE, C. The danger of a single story. 2009. Disponivel em: <http://www. youtube.com/watch?v=D9Ihs241zeg>. Acesso em: 20 out. 2012.

ARISTÓTELES. Poética. São Paulo: Ars Poética, 1992.

AUSTIN, J. L. Quando dizer é fazer: palavras e ação. Tradução de Danilo Marcondes. Porto Alegre: Artes Médicas, 1990.

BAMBERG, M. Who am I?: narration and its contribution to self and identity. Theory \& Psychology, New York, v. 21, n. 1, p. 3-24, 2011.

BAMBERG, M.; GEORGAKOPOULOU, A. Small stories as a new perspective in narrative and identity analysis. Text \& Talk, [S.1.], v. 28, n. 3, p. 377-396, 2008.

BARNARD, I. Queer race: cultural interventions in the racial politics of queer theory. New York: Peter Lang, 2004.

BAUMAN, R. Story, performance and event: contextual studies of oral narrative. Cambridge: CUP, 1986.

BAUMAN, R.; BRIGGS, C. Poetics and performance as critical perspectives on language and social life. American Review of Anthropology, [S.1.], v. 19, p. 59-88, 1990.

BAUMAN, Z. Modernidade líquida. Tradução de Plínio Dentzien. Rio de Janeiro: Jorge Zahar, 2001.

BISPO, C. Candaces: dois discursos, duas representações. Nearco: Revista Eletrônica de Antiguidade, Rio de Janeiro, n. II, p. 7-16, 2009.

BROCKMEIER, J.; OLSON, D. R. The literacy episteme: from Innis to Derrida. In: OLSON, D. R.; TORRANCE, N. (Org.). The cambridge handbook of literacy. Cambridge: Cambridge University Press, 2009. p.03-23.

BRONCKART, J. P. Atividade de linguagem, textos e discursos: por um interacionismo sociodiscursivo. Tradução de Anna Raquel Machado e Péricles Cunha. 2. ed. São Paulo: EDUC, 2007. 
BRUCE, B. C.; BISHOP, A. P. New digital and community inquiry. In: COIRO, J. et al. (Org.). Handbook of research on new literacies. London: Lawrence Erlbaum Associates, 2008. p. 699-742.

BUTLER, J. Performative acts and gender constitution: an essay in phenomenology and feminist theory. In: BIAL, H. (Org.). The performance studies reader. New York: Routledge, 2004. p.154-166.

CARNEIRO, S. Mulheres em movimento. Estudos Avançados, São Paulo, v. 17, p. 117-132, 2003.

CERCAS, J. A velocidade da luz. Tradução de A. F. Borges. Rio de Janeiro: Relume-Diernará, 2007.

COSTA DE PAULA, R. "Não quero ser branca não. Só quero um cabelo bom, cabelo bonito": performances de corpos/cabelos de adolescentes negras em práticas informais. 2010. 313f. Tese (Doutorado em Linguística Aplicada) -Instituto de Estudos da Linguagem, Universidade Estadual de Campinas, Campinas, 2010.

Construindo consciência das masculinidades negras em contexto de letramento escolar: uma pesquisa-ação. In: MOITA LOPES, L. P. (Org.). Discursos de identidades. Campinas: Mercado de Letras, 2003. p.181-208.

COUPLAND, N. Style: language variation and identity. Cambridge: Cambridge University Press, 2007.

COUPLAND, N. et al. Narrative demands, cultural performances and evaluation: teenage boys' stories for their peers. In: THORNBORROW, J.; COATES, J. The sociolinguistics of narrative. Amsterdam: John Benjamins, 2005. p.67-88.

DERRIDA, J. Signature event context. In: Limited inc. Evanston: Northwestern University Press, 1988. p. 1-23.

DOBSON,T.; WILLINSKY, J. Digital literacy. In: OLSON, D. R.; TORRANCE, N. (Org.). The cambridge handbook of literacy. Cambridge: Cambridge University Press, 2009. p. 286-312.

FERREIRA, A J. Formação de professores de línguas: histórias de professoras negras e brancas de inglês e suas experiências com o racismo. In:

Formação de professores de línguas: investigações e intervenções. Cascavel: Edunioeste, 2009. p. 67-84.

Formação de professores raça/etnia: reflexões e sugestões de materiais de ensino. Cascavel: Coluna do Saber, 2006.

GIDDENS, A. As consequências da modernidade. São Paulo: Ed. da UNESP, 1991. 
GOFFMAN, E. Performances: belief in the part one is playing. 1959. In: BIAL, H. (Org.). The performance studies reader. New York: Routledge, 2004. p. 59-63.

GUIMARÃES, M. J. L. Jr. Doing anthropology in cyberspace: fieldwork boundaries and social environment. In: HINES, C. Virtual methods: issues in social research on the internet. Oxford: Berg Publishers, 2005. p. 157-170.

HENRIQUE, C. Reconstrução: uma abordagem sócio-histórica sobre o racismo à brasileira. Revista Urutágua, Maringá, n.12, p.01-11, abr./maio/jun./jul. 2007. Disponível em: <http://www.urutagua.uem.br/012/12henrique.pdf>. Acesso em: 11 nov. 2012.

HINES, C. Virtual methods: issues in social research on the internet. Oxford: Berg, 2005.

Virtual ethnography. London: Sage Publications, 2000.

HOOKS, B. Teaching to transgress: education as the practice of freedom. New York: Routledge, 1994.

JENKINS, H. Cultura da convergência. São Paulo: Aleph, 2008.

KRESS G.; VAN LEEUWEN, T. Reading images: the grammar of visual design. London: Routledge, 1996.

LABOV,W. Language in the inner city. Philadelphia: University of Pennsylvania Press, 1972.

LANKSHEAR, C.; KNOBEL, M. (Org.). Digital literacies: concepts, policies and practices. New York: Peter Lang, 2008.

LOURO, G. Um corpo estranho. Belo Horizonte: Autêntica, 2004.

LOXLEY, J. Performativity. Londres: Routledge, 2007.

MACHADO, A. R. et al. Relações entre linguagem e trabalho educacional: novas perspectivas e métodos no quadro do interacionismo sociodiscursivo. In: MACHADO, A. R.; CRISTOVÃO, V. L. L.; ABREU-TARDELLI, L. S. (Org.). Linguagem e educação: o trabalho do professor em uma nova perspectiva. Campinas: Mercado de Letras, 2009. p.15-29.

MARTIN,A. Digital literacy and the "digital society". In: LANKSHEAR, C.; KNOBEL, M. (Org.). Digital literacies: concepts, policies and practices. New York: Peter Lang, 2008. p.151-176.

MELO, G. C. V.; MOITA LOPES, L. P. As performances discursivo-identitárias de mulheres negras em uma comunidade para negros na Orkut. Delta, São Paulo, v. 29, n. 2, p. 237-265, 2013. 
MISHLER, E. G. Narrativa e identidade: a mão dupla do tempo. In: BASTOS, L. C.; MOITA LOPES, L. P. Identidades: recortes multi e interdisciplinares. Campinas: Mercado das Letras, 2002. p. 97-119.

MOITA LOPES, L. P. Os espaços da narrativa como construto teóricometodológico na investigação em linguística aplicada. Rio de Janeiro: Ed. da UFRJ, 2010.

A performance narrativa do jogador Ronaldo como um fenômeno sexual em um jornal carioca: multimodalidade, posicionamento e iconicidade. Revista da ANPOLL, Florianópolis, v.27, p.129-160, 2009.

On being white, heterosexual and male in a brazilian school: multiple positionings in oral narratives. In: FINNA, A. de; SCHIFFRIN, D.; BAMBERG M. (Org.). Discourse and identity. Cambridge: Cambridge University Press, 2006. p. 288-313.

Discursos de identidades. Campinas: Mercado das Letras, 2003.

MOITA LOPES, L. P.; BASTOS, L. Para além da identidade: fluxos, movimentos e trânsitos. Belo Horizonte: Ed. da UFMG, 2010. p. 9-14.

MUNANGA, K. Negritude usos e sentidos. São Paulo: Ática, 1986.

PENNYCOOK, A. Language as local practice. Londres: Routledge, 2010.

. Performance and performativity. In: PENNYCOOK, A. Global englishes and transcultural flows. New York: Routledge, 2007. p. 58-77.

. Uma linguística aplicada transgressiva. In: MOITA LOPES, L. P. (Org.). Por uma linguística aplicada interdisciplinar. São Paulo: Parábola, 2006. p. 67-84.

PIZA, E. S. P. O caminho das águas: estereótipos de personagens femininas negras na obra para jovens, de escritoras brancas. 1995. 216 f. Dissertação (Mestrado em Psicologia Social) - Programa de Estudos Pós-Graduados em Psicologia Social, Pontifícia Universidade Católica de São Paulo, São Paulo, 1995.

PRETA. Tornando-se preta num segundo nascimento. 21 out. 2009. Blog pessoal. Disponível em: <http://eumulherpreta.blogspot.com.br/2009/10/ tornando-se-preta-num-segundo.html>. Acesso em: 25 out. 2012.

PROPP, V. I. Morfologia do conto maravilhoso. Rio de Janeiro: ForenseUniversitária, 2006.

RAMPTON, B. Late modern language, interaction and schooling. In:

Language in late modernity: interaction in an urban school. Cambridge: Cambridge Press, 2006. p. 03-38. 
SANTOS, B. de S. Do pós-moderno ao pós-colonial e para além de um e outro. Revista de Ciências Sociais e Humanas em Língua Portuguesa, São Paulo, n. 6/7, p. 15-38, 2008.

SODRÉ, M. Claros e escuros. Rio de Janeiro: Vozes, 1999.

SOMMERVILLE, S. B. Queering the color line: race and the inventions of homosexuality in america culture. Durham: Duke University, 2000.

SULLIVAN, N. A critical introduction to queer theory. New York: New York University Press, 2003.

TELLES, E. Racismo à brasileira: uma nova perspectiva sociológica. Rio de Janeiro: Relume-Dumará, 2003.

THORNBORROW, J.; COATES, J. The sociolinguistics of narrative: identity, performance, culture. In:

John Benjamins, 2005. p.1-16. The sociolinguistics of narrative. Amsterdam:

THREADGOLD, T. Performing theories of narrative: theorizing narrative performance. In: THORNBORROW, J.; COATES, J. The sociolinguistics of narrative. Amsterdam: John Benjamins, 2005. p. 261-278.

VENN, C. Occidentalism, modernity and subjectivity. Londres: Sage, 2000.

VOLOSHINOV, V. N. Marxismo e filosofia da linguagem. São Paulo: Hucitec, 1981.

WILCHINS, R. Queer theory, gender theory: an instant primer. Los Angeles: Alyson Books, 2004.

WORTHAM, S. Narratives in action. New York: Teacher College Press, 2001.

Recebido em junho de 2013.

Aprovado em setembro de 2013. 
